\title{
Removal of Methylene Blue Using Chemically Modified Sugarcane Bagasse
}

\author{
Handojo Djati Utomo1*, Ru Yi Natalie Phoon1, Zhonghuan Shen', Li Hui Ng1, \\ Zheng Bang Lim² \\ ${ }^{1}$ Division of Civil Engineering, School of Architecture and the Built Environment, Singapore Polytechnic, \\ Singapore City, Singapore \\ ${ }^{2}$ Advanced Material Technology Centre, Technology Development Office, Singapore Polytechnic, Singapore City, \\ Singapore \\ Email: "han@sp.edu.sg,
}

Received 2 January 2015; accepted 22 March 2015; published 26 March 2015

Copyright $(2015$ by authors and Scientific Research Publishing Inc.

This work is licensed under the Creative Commons Attribution International License (CC BY).

http://creativecommons.org/licenses/by/4.0/

(c) (i) Open Access

\begin{abstract}
Methylene Blue (MB) has been found to be one of the most common dyes used in the industries. Adsorption process using Activated Carbon (AC) has been proven to be able to remove MB effectively but the treatment cost using the adsorbent is considered expensive due to its high energy cost. Sugarcane Bagasse (SGB) is an agricultural by-product and abundantly available material in many developing countries. FTIR and XRD were used to confirm the existence of ligno-cellulose content of SGB after experiencing various chemical treatments. SGB had 5 - 40 folds higher MB removal capability than commercial activated carbon, depending on the $\mathrm{pH}$ of water medium and the type of SGB. SGB showed a much better performance in adsorbing MB in alkaline environment than in acidic environment. Langmuir adsorption isotherm model was able to estimate the removal capacity of non-chemical treated SGB (NSGB) and $\mathrm{CaCl}_{2}$ treated SGB (CSGB) at $84.7458 \mathrm{mg} / \mathrm{g}$ and $35.2113 \mathrm{mg} / \mathrm{g}$ respectively. An extremely higher MB removal capacity was found for BSGB due to the complexity of the surface site after chemical treatment. NaOH treated SGB (BSGB) with low lignin residue content was the most favourable adsorbent for MB adsorption.
\end{abstract}

\section{Keywords}

Adsorbent, Methylene Blue, Ligno-Cellulose, Sugarcane Bagasse

\section{Introduction}

Dye is a natural or synthetic material that adds a specific colour to the material it is being applied to. Dye has an "Corresponding author. 
ionising and aromatic organic compound that forms an affinity to substrates and binds to them. The discovery of the first synthetic dye led to the transition from natural dye to synthetic dye manufacturing in the early twentieth century [1]. Currently, synthetic dyes are used in a wide range of industries from commodity manufacturing such as textile making [2]-[4], paper production [5] and food technology [6] [7], to energy generation such as light-harvesting arrays [8] and photoelectrochemical cells [9]. While synthetic dyes are increasingly used over natural dyes due to their lower costs and cheaper production [10], synthetic dyes have their own negative impacts. With their visible colour, synthetic dyes reduce the light penetration into the wastewater and adversely affect aquatic growth and photosynthesis. They can also bring severe and/or long-term health effects to organisms [11]. Figure 1 shows a commonly used synthetic dye of Methylene Blue (MB), which has an empirical formula of $\mathrm{C}_{16} \mathrm{H}_{18} \mathrm{ClN}_{3} \mathrm{~S}$.

Due to their complex chemical structure, synthetic dyes are harder to biodegrade and thus more resistant to conventional biological treatment. The traditional physical and chemical processes are also expensive and ineffective in the treatment of various dyes in wastewater [13].

Adsorption is increasingly being used for its high removal rate of dye from wastewater [14] [15] and its low operation cost [16]. Adsorption is a process where a substance adheres to the surface of the adsorbent as compared to absorption where the entire volume of the substance dissolves into the adsorbent. While the absorption substance can only be liquid, adsorption substance can be a gas, liquid or dissolved solid [17]. Characteristics of adsorbents include porosity, pore structure and the nature of the adsorbent surface; these will determine their effectiveness in removing dye waste [18]. While activated carbon (AC) is one of the most effective adsorbents for dye waste, commercially available AC is expensive [19]. However, recent research has shown that suitable adsorbent materials can also be found in a wide range of materials that are inexpensive and commonly available. Industrial and agricultural by-products can be modified to increase their adsorption capacity to form AC. They include waste paper [20], rice hull [21], and wood waste [22]. Some studies on adsorption of different dyes onto sugarcane bagasse (SGB) have been reported recently [23]-[25]. Sugarcane bagasse contained approximately $30 \%-50 \%$ of cellulose and $20 \%-24 \%$ of lignin [26].

In this study, the effectiveness of sugarcane bagasse biosorbent for MB removal was investigated. Adsorption studies were conducted in batches according to various parameters such as initial concentration of MB adsorbate, SGB adsorbent, adsorption time and $\mathrm{pH}$. Chemical pre-treatment was conducted to improve the adsorptive properties of SGB. Material characterisation was conducted using FTIR and XRD. The MB experimental data were fitted onto Langmuir and Freundlich adsorption isotherm models to determine the SGB removal capacity. The objectives of this study were to investigate the MB removal capability of SGB in comparison to commercial activated carbon and to investigate the determining factor that can enhance MB adsorption onto SGB, whether from the change of SGB adsorbent characteristic or the change of various experimental conditions.

\section{Methodology, Equipment and Materials}

\subsection{Pre-Treatment of SGB to Prepare NSGB, CSGB and BSGB}

An estimated $5 \mathrm{~kg}$ of SGB was collected from one of the local drink stall in hawker centre using a plastic bag. The soft, pale fibres were collected from the inner side of SGB by using hands to tear it off. Approximately $30 \mathrm{~g}$ of SGB were weighed using a three-decimal place mass balance before being rinsed with $800 \mathrm{~mL}$ of tap water. Further tap water rinsing was conducted to ensure SGB free from any attached dust or fine particles. After that, $800 \mathrm{~mL}$ of deionized water were used to sanitise the SGB. The SGB were placed on an aluminium tray and dried in an oven (Memmert) at $103^{\circ} \mathrm{C}$ overnight to fully remove water moisture. The SGB was collected on the next day and it was cut into smaller pieces using scissors. The smaller pieces of SGB were blended using SONA Electric Blender until becoming fine particles. The blended SGB were then sieved by passing through a $2.0 \mathrm{~mm}$ sieve (ASTM) and collected in a $850 \mu \mathrm{m}$ sieve (ASTM E11). The SGB were then stored as NSGB in a labelled<smiles>CN=c1ccc2nc3ccc(N(C)C)cc3sc-2c1</smiles>

Figure 1. Structure of MB [12]. 
container. A further treatment was conducted to prepare CSGB and BSGB. The CSGB was prepared by adding $10 \mathrm{~g}$ of NSGB in $500 \mathrm{~mL}$ of $0.0248 \mathrm{~mol} / \mathrm{L}$ calcium chloride $\left(\mathrm{CaCl}_{2}\right)$ solution to mineralise SGB and remove lignin content, similar to Rowell [27] when trying to remove lignin from woods but using sodium chloride. The mixture was manually shaken for a couple of minutes before being left overnight. SGB was filtered and dried in the oven overnight before being stored as CSGB. The BSGB was prepared by mixing $2 \mathrm{~g}$ of NSGB with concentrated $1 \mathrm{M}$ of $\mathrm{NaOH}$ in $500 \mathrm{~mL}$ beaker glass to delignify SGB [28]. The mixture was left overnight and the SGB was filtered and dried in the oven the next day for approximately 4 hours. The SGB was then stored as BSGB in a labelled container. The same pre-treatment procedure of SGB was repeated after the existing supply was used up. Pale yellow NSGB samples will turn darker yellow after calcium chloride and alkaline treatment. BSGB also showed the darkest yellow among three samples and fragile and amorphous. Figure 2 shows samples of NSGB, CSGB \& BSGB.

\subsection{Characterisation of SGB Using FTIR and XRD Instruments}

Material characterisation was conducted using two available analytical instruments of FTIR and XRD to determine various functional groups including lignin existence, existence of cellulose and size of crystalline cellulose from NSGB, CSGB and BSGB samples. The dried samples were grinded and embedded in $\mathrm{KBr}$ pellets. IR spectra of the samples were recorded by using IRPrestige-21 FTIR spectrophotometer (Shimadzu). The spectra were recorded in the transmission band mode in the range of $4000-400 \mathrm{~cm}^{-1}$. Crystallinity of the samples was determined by X-ray diffraction using D8 ADVANCE diffractometer (Bruker). The diffraction spectrum was taken by the $\theta-2 \theta$ method. Samples were scanned from $2 \theta=10^{\circ}$ to $70^{\circ}$ with a step size of $0.02^{\circ}$. The samples' crystallinity was determined as the percentage as follows:

$$
C r I=\frac{\left[I_{002}-I_{a m}\right]}{I_{002}} \times 100 \%
$$

where,

$I_{002}=$ the maximum intensity of the (002) lattice diffraction $\left(2 \theta \approx 22^{\circ}\right)$;

$I_{a m}=$ the intensity at $2 \theta \approx 15^{\circ}-18^{\circ}$ (amorphous).

The average size of the crystallites was calculated from the Scherrer equation, which was based on the width of the diffraction patterns obtained in the X-ray reflected crystalline region. In the present study, the crystallite sizes were determined by using the diffraction pattern obtained from the $002(h k l)$ lattice planes of samples using the following formula:

$$
D_{(h k l)}=\frac{K \lambda}{B_{(h k l)}} \cos \theta
$$

where,

$(h k l)=$ the lattice plane;

$D_{(h k l)}=$ the size of crystallite;

$K=$ the Scherrer constant (taken as 0.9);

$\lambda=$ the $\mathrm{X}$-ray wavelength $(0.154 \mathrm{~nm})$;

$B_{(h k l)}=$ the FWHM (full width half maximum) of the measured $h k l$ reflection;

$2 \theta=$ the corresponding Bragg angle (reflection angle).

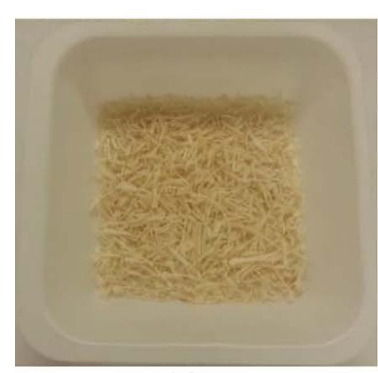

NSGB

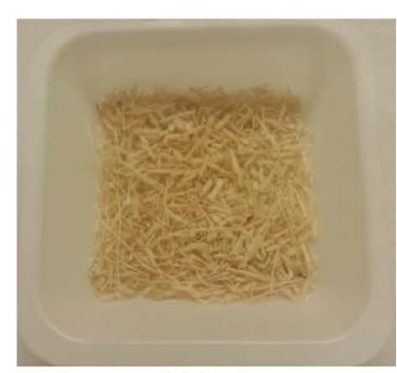

CSGB

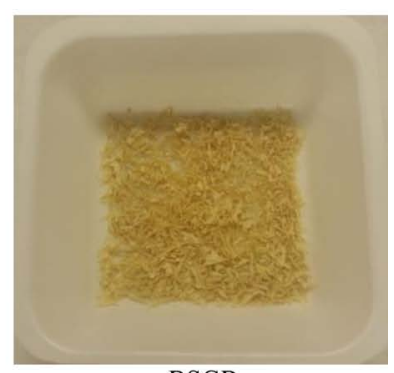

BSGB

Figure 2. Samples of NSGB, CSGB \& BSGB. 


\subsection{Preparation of $10 \mu \mathrm{mol} / \mathrm{L}(3.739 \mathrm{mg} / \mathrm{L})$ of MB Stock Solution}

Using a four-decimal-place electronic mass balance, $0.0019 \mathrm{~g}$ of powered MB was accurately weighed out. It was then dissolved completely in $500 \mathrm{~mL}$ of deionized water before being transferred into a $500 \mathrm{~mL}$ storage bottle to make a $10 \mu \mathrm{mol} / \mathrm{L}$ ( $3.739 \mathrm{mg} / \mathrm{L}$ ) MB solution. The storage bottle was wrapped with aluminium foil to prevent de-colourisation of the solution as MB is naturally very sensitive to light. The absorbance of the various MB standard solutions was measured using a UV Spectrophotometer (TechComp UV 1100 Spectrophotometer), at two reference wavelengths of $609 \mathrm{~nm}$ and $665 \mathrm{~nm}$. Both wavelengths were compared based on its regression value, and $665 \mathrm{~nm}$ was found to have the best regression value $\left(r^{2} \approx 1\right)$ [22]. Thus, the wavelength of $665 \mathrm{~nm}$ was selected for determining the remaining concentration of $\mathrm{MB}$ after batch adsorption experiment.

\subsection{Batch Adsorption Experiment}

Various amount of SGB were weighed using a four-decimal-place mass balance and placed into $50 \mathrm{~mL}$ test tubes filled with $30 \mathrm{~mL}$ of $10 \mu \mathrm{mol} / \mathrm{L} \mathrm{MB}$ solution. The MB solution in the test tubes were mixed thoroughly using an adjustable rotator (Digital Feedback Controlled Rotator) (Figure 3) at $30 \mathrm{rpm}$ and subsequently centrifuged for 1 minute in a centrifuge machine (Hettich Zentrifugen, D-78532 Tuttlingen) (Figure 4) at $6000 \mathrm{rpm} .10 \mathrm{~mL}$ of each sample was withdrawn using a dropper and put into $15 \mathrm{~mL}$ test tubes to separate SGB from the mixture. The supernatant liquid was then extracted using a dropper and recorded the absorbance using a UV Spectrophotometer (TechComp UV 1100 Spectrophotometer) (Figure 5). These procedures were used to determine the optimum adsorption time, effect of $\mathrm{pH}$ and effect of SGB concentration on the removal rate of MB. To investigate the effect of $\mathrm{pH}$, some drops of concentrated $\mathrm{H}_{2} \mathrm{SO}_{4}$ and $\mathrm{NaOH}$ were added into $10 \mu \mathrm{mol} / \mathrm{L}$ of $\mathrm{MB}$ solutions for a $\mathrm{pH}$ alteration. Subsequently, $0.833 \mathrm{~g} / \mathrm{L}$ of SGB was put into the test tube to obtain various $\mathrm{pH}$. After reaching the equilibrium time, the result was measured using the pH meter (EUTECH) (Figure 6). Experimental analysis of sample was setup in duplicates and relative standard deviation (RSD) was calculated for each result.

\subsection{Determining the Removal Rate of MB}

In quantitative analysis, the adsorptive capacity of adsorbents of SGB was analysed as follows. The removal rate of MB was expressed as $\mathrm{mg} / \mathrm{g}$ and calculated using the following formula:

$$
\text { Mole of MB removed }(\mathrm{mol})=\left[\left(C_{i}-C_{f}\right) \times 10^{-6}\right] \times \frac{\text { Volume of MB used }}{1000}
$$

Mass of MB removed $(\mathrm{mg})=$ Mole of MB removed $\times 373.90 \mathrm{~g} / \mathrm{mol} \times 1000$

$$
\text { Removal Rate of MB }(\mathrm{mg} / \mathrm{g})=\frac{\text { Mass of MB removed }(\mathrm{mg})}{\text { Mass of bagasse }(\mathrm{g})}
$$

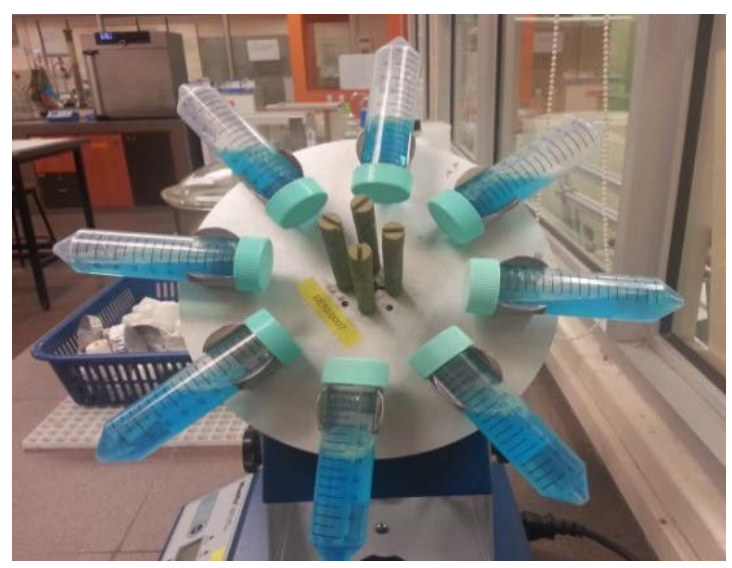

Figure 3. Rotator (Digital Feedback Controlled Rotator) with tested samples of SGB and MB. 


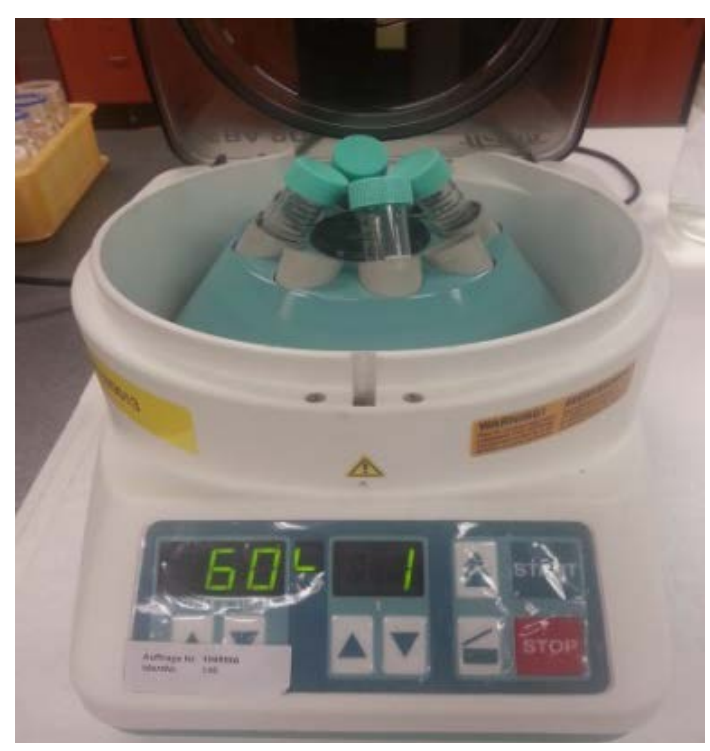

Figure 4. Centrifuge Machine (Hettich Zentrifugen) with tested samples of SGB and MB.

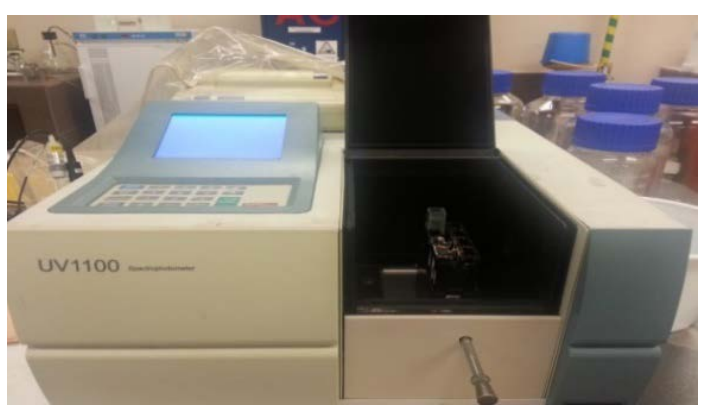

Figure 5. UV Spectrophotometer (TechComp UV 1100 Spectrophotometer).

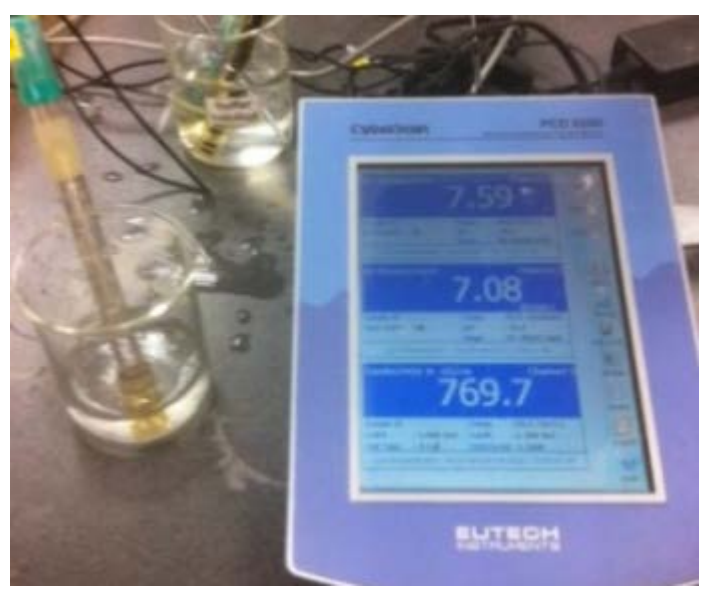

Figure 6. pH Meter (EUTECH instruments).

where,

$C_{i}=$ Initial concentration of MB solution $(\mu \mathrm{mol} / \mathrm{L})$;

$C_{f}=$ Final concentration of MB solution $(\mu \mathrm{mol} / \mathrm{L})$;

Molecular Weight of MB $=373.90 \mathrm{~g} / \mathrm{mol}$. 


\subsection{Determining the MB Removal Capacity Using Langmuir and Freundlich Models}

In quantitative analysis, the adsorption data was analysed by fitting them to Langmuir and Freundlich equations [29]. Each linearized equation is presented below:

Linearized Langmuir Isotherm equation:

$$
\frac{1}{x}=\frac{1}{b C e X m}+\frac{1}{X m}
$$

where,

$X=$ Removal rate of $\mathrm{MB}(\mathrm{mg} / \mathrm{g})$;

$X_{m}=$ Monolayer capacity of SGB in adsorbing MB (mg/g);

$C_{e}=$ Final concentration of MB solution $(\mathrm{mg} / \mathrm{L})$;

$b=$ Equilibrium binding constant of the MB adsorption (L/mg).

Linearized Freundlich Isotherm equation:

$$
\log X=\log K+\frac{1}{n} \log C_{e}
$$

where,

$X=$ Removal rate of $\mathrm{MB}(\mathrm{mg} / \mathrm{g})$;

$C_{e}=$ Final Concentration of MB Solution $(\mathrm{mg} / \mathrm{L})$;

$K=$ Equilibrium constant that indicate a measure of multi-layer adsorption capacity (mg/g);

$1 / n=$ Equilibrium constant that indicate a measure of intensity of adsorption.

The plots of $1 / X$ versus $1 / C_{e}$ and $\log X$ versus $\log C_{e}$ were made to test the data fitness to the Langmuir and Freundlich adsorption models, respectively.

\section{Results and Analysis}

\subsection{SGB Characterisation Using FTIR and XRD}

Figure 7 represents the FTIR spectra of samples BSGB, CSGB and NSGB. The bands at $3400 \mathrm{~cm}^{-1}$ and 2910 $\mathrm{cm}^{-1}$ are assigned to O-H stretching and $\mathrm{C}-\mathrm{H}$ stretching and exist in all three samples. NSGB has the highest intensity at band of $3400 \mathrm{~cm}^{-1}$ (O-H stretching) among the samples. Band at $1740 \mathrm{~cm}^{-1}$ represent $\mathrm{C}=\mathrm{O}$ stretching which is absent in BSGB sample. The band at $1640 \mathrm{~cm}^{-1}$ is assigned to $\mathrm{O}-\mathrm{H}$ bending of absorbed water. Moreover, the conjugated $\mathrm{C}=\mathrm{O}$ stretching lignin also appeared at this wavenumber. The lignin-associated bands at 1600 $\mathrm{cm}^{-1}$ and $1510 \mathrm{~cm}^{-1}$, which are assigned to aromatic skeletal vibrations, have low intensity (weak signals) in BSGB sample, indicating low residue lignin content. The band at $1430 \mathrm{~cm}^{-1}$ is assigned to the $\mathrm{CH}_{2}$ scissoring motion and it appeared in all samples. Bands at $1380 \mathrm{~cm}^{-1}$ and $1320 \mathrm{~cm}^{-1}$ are also assigned to $\mathrm{C}-\mathrm{H}$ (methyl) group of bonding and they appear in all samples. Band at $1260 \mathrm{~cm}^{-1}$ is also assigned to C-H (methyl) group of bonding but the intensities of different samples are different, with BGSB having the lowest intensity while NSGB having the highest intensity. Band at around $1040-1060 \mathrm{~cm}^{-1}$ is assigned to C-O (primary alcohol) which the CSGB is having the lowest intensity at this band. Besides, broad band at $650-700 \mathrm{~cm}^{-1}$ which assigned to C-H (substituted alkene) was found only in CSGB sample.

Figure 8 represents the XRD results of the three samples (BSGB, CSGB and NSGB). The diffraction spectrum at $22^{\circ}$ and $15^{\circ}-18^{\circ}$ showed the existence of cellulose. BSGB showed the highest intensity at $22^{\circ}$ at the intensity of 002 among the samples [28]. However, the crystallinity of cellulose $\operatorname{CrI}$ Equation (1), is $68.4 \%, 73.4 \%$, 21.4\% for BSGB, CSGB and NSGB, respectively. CSGB, although not having highest intensity at 002 peaks as compared to BSGB, has the highest value of $\operatorname{CrI}(73.4 \%)$ due to the lowest amount of amorphous content in the corresponding solid, relevant to the CSGB and BSGB physical appearance more yellowish in colour and less amorphous. NSGB had the similar intensity of 002 peaks with CSGB, showed the lowest value of CrI (21.4\%) among three samples due to its highest amount of amorphous content. In addition, according to the Scherrer's Equation (2), the sizes of the crystallite for BSGB, CSGB and NSGB are 3.245, 3.327 and $3.196 \mathrm{~nm}$, respectively with the details of 002 peaks as shown in Table 1. Although NSGB have the smallest crystallite size among the samples, all samples have very similar crystallite size. Thus, the effect of NSGB, BSGB and CSGB crystallite size on MB removal rate could be inconclusive. 


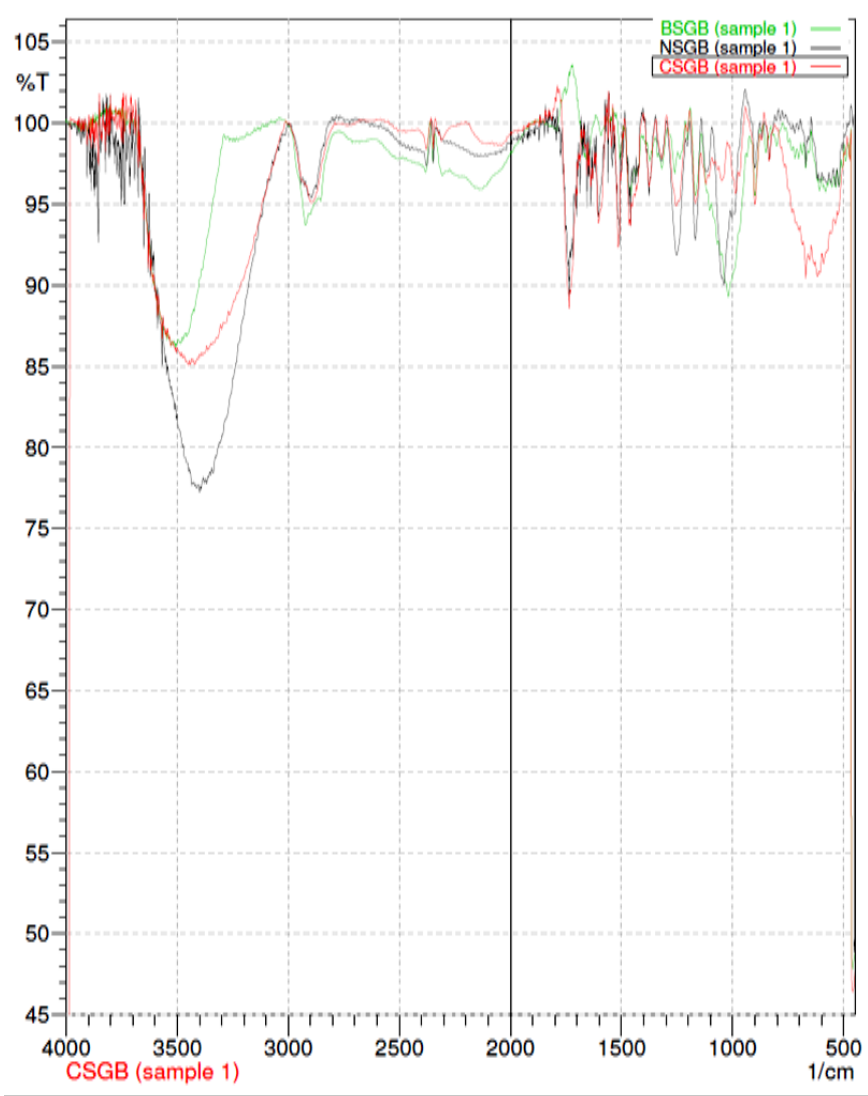

Figure 7. FTIR spectra of samples BSGB, CSGB and NSGB recorded by using IRPrestige-21 FTIR spectrophotometer (Shimadzu).

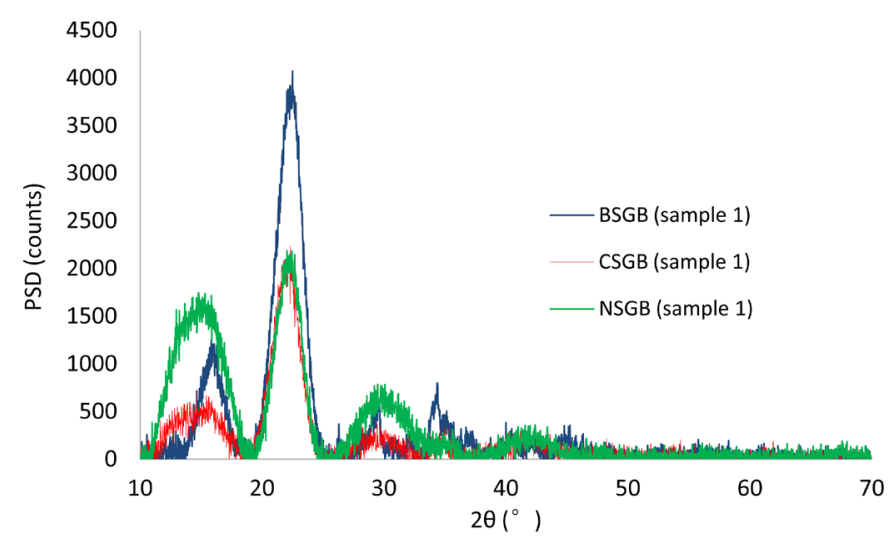

Figure 8. XRD spectra of samples BSGB, CSGB and NSGB.

Table 1. Crystallite size measurement of samples BSGB, CSGB and NSGB at 002 peaks.

\begin{tabular}{ccccccc}
\hline \multicolumn{7}{c}{} \\
Types of sample & $2 \theta$ & $\theta$ & $\cos \theta$ & FWHM $\beta$ (degree) & FWHM $\beta$ (radian) & Crystallite size D (nm) \\
\hline BSGB & 22.2850 & 11.1425 & 0.981150 & 2.494 & 0.043529 & 3.245 \\
CSGB & 22.3920 & 11.1960 & 0.980969 & 2.433 & 0.042464 & 3.327 \\
NSGB & 22.0240 & 11.0120 & 0.981587 & 2.531 & 0.044174 & $\mathbf{3 . 1 9 6}$ \\
\hline
\end{tabular}




\subsection{Effect of Adsorption Time on the Removal Rate of $M B$}

Figure 9 shows that the MB adsorption rate was occurring very fast. Within 15 minutes, the MB could be adsorbed onto NSGB surface. The experiment was repeated three times by increasing the concentration of NSGB from $0.833 \mathrm{~g} / \mathrm{L}$ to $1.667 \mathrm{~g} / \mathrm{L}, 3.333 \mathrm{~g} / \mathrm{L}$ and up to $8.333 \mathrm{~g} / \mathrm{L}$ (10 folds than the earliest NSGB concentration). The higher the NSGB concentration showed the smaller MB removal rate of MB per gram of NSGB. Figure 7 also shows an increasing order of the removal rate of MB from the highest to the lowest SGB concentration i.e. 8.333 $\mathrm{g} / \mathrm{L}, 3.333 \mathrm{~g} / \mathrm{L}, 1.667 \mathrm{~g} / \mathrm{L}$ and $0.833 \mathrm{~g} / \mathrm{L}$ of NSGB in every single recorded adsorption time, before reaching plateau. It suggested that MB might be attached onto active SGB surface site for every gram of SGB before reaching equilibrium adsorption time. In addition, although the lowest concentration of NSGB of $0.833 \mathrm{~g} / \mathrm{L}$ gave the highest $\mathrm{MB}$, the optimum adsorption time to reach its plateau was the latest, approximately twice longer (30 minutes) than the other NSGB concentrations. Thus, it showed that, at a fixed MB concentration of $10 \mu \mathrm{M}$ (3.739 mg/L), the lower NSGB concentration, the more time needed for MB to be fully adsorbed onto the active surface sites of the NSGB. In the next batch of experimental studies, a minimum 30 minutes equilibrium time was used.

\subsection{Effect of pH Value on the Removal Rate of MB and AC}

Following the results in Figure 9, the lower SGB concentration will result in more MB adsorbed per gram of SGB. Therefore, $0.833 \mathrm{~g} / \mathrm{L}$ SGB is used to determine the range of $\mathrm{pH}$ that the SGB could be used to adsorb MB. Figure 10(a) showed that the SGB could remove approximately $4 \mathrm{mg} / \mathrm{g}$ to $4.5 \mathrm{mg} / \mathrm{g}$ of $\mathrm{MB}$ at higher $\mathrm{pH}$ range, from $\mathrm{pH} 8$ to 12. At the intermediate $\mathrm{pH}$, approximately $4<\mathrm{pH}<8$, the BSGB showed the highest among the other types of NSGB and CSGB. The result might reveal that the delignification using concentrated $\mathrm{NaOH}$ may increase the MB adsorptive properties of SGB. Minimum lignin residue content was found in BSGB after FTIR scanning as shown Figure 7. Lignin removal from SGB powder using acidified $\mathrm{NaCl}$ was also conducted by Rowell [27] to improve the adsorptive properties of SGB. Chemical treatment using $\mathrm{NaOH}$ may open up more active sites of cellulose, which were responsible for MB adsorption onto SGB surface. Begum and Mahbub [26] found that cellulose in SGB could effectively adsorb MB than lignin in SGB, which was on the contrary than the finding from Filho et al. [30]. In acidic environment $(\mathrm{pH}<4)$, the rich cellulose content of BSGB could be less significant in adsorbing MB. Figure 10(a) showed that BSGB was less attractive than NSGB in adsorbing MB, but it was still better than CSGB in adsorbing MB, making the last comparison becoming inconclusive. Comparing to AC in removing an initial $10 \mu \mathrm{M}$ of MB (Figure 10(b)), the three types of SGBs were significantly higher at every $\mathrm{pH}$ level. In acidic environment $(\mathrm{pH}<4)$, the AC-GR 17 and GR 19 were more favourable in adsorbing $\mathrm{MB}$ than in the intermediate $\mathrm{pH}$ and in higher alkaline environment. At approximate extreme $\mathrm{pH}$ of 4.4, the MB removal rates of CSGB, NSGB and BSGB were 6, 25, 25 folds respectively, higher than the average MB removal rates of AC-GR 17 and GR 19 with nominal MB removal rate of $0.145 \mathrm{mg} / \mathrm{g}$. In alkaline environ-

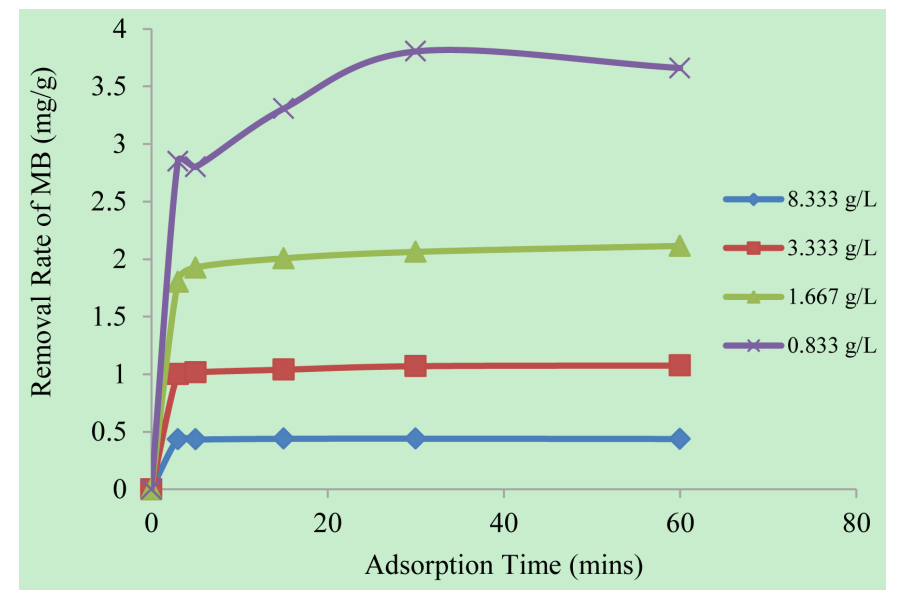

Figure 9. MB removal rate from various NSGB concentrations at different adsorption time. MB initial concentration was $3.739 \mathrm{mg} / \mathrm{L}$ with the measured $\mathrm{pH}$ of 5 . 


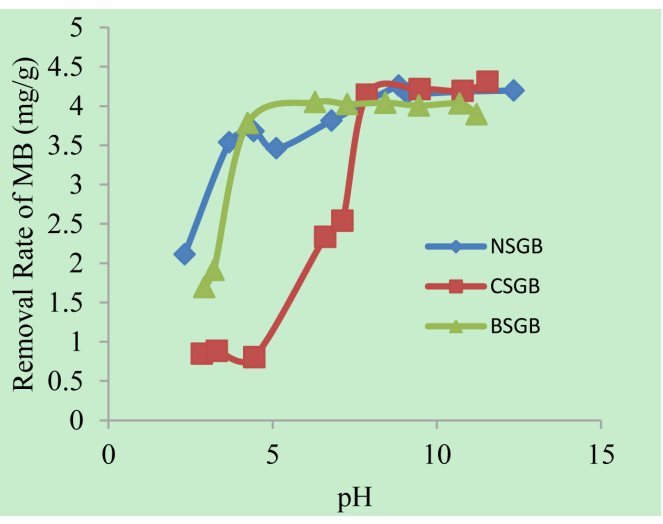

(a)

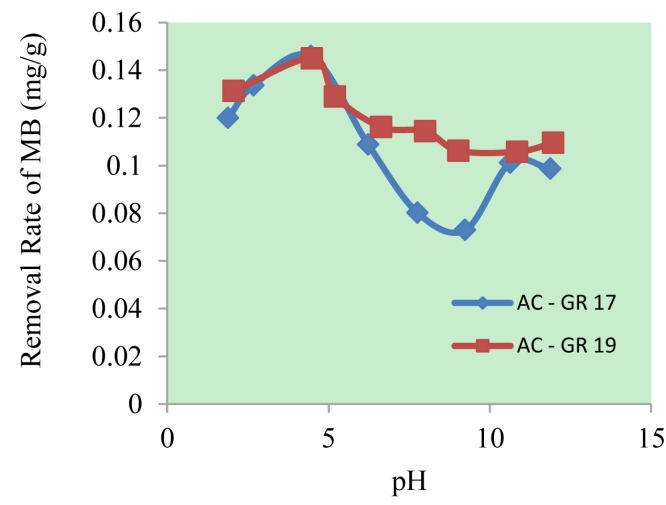

(b)

Figure 10. (a) above left, (b) above right: Removal rate of MB onto (a) NSGB, CSGB \& BSGB and (b) onto AC-GR 17 \& GR 19 at different $\mathrm{pH}$. Initial MB concentration was $10 \mu \mathrm{M}(3.739 \mathrm{mg} / \mathrm{L})$ with equilibration time. Each SGB concentration was $0.833 \mathrm{~g} / \mathrm{L}$ and AC concentration was $25 \mathrm{~g} / \mathrm{L}$.

ments, where SGBs are more favourable in adsorbing MB, the difference of MB removal rate could go up to 40 folds higher than those ACs in removing the same initial MB of $10 \mu \mathrm{M}(3.739 \mathrm{mg} / \mathrm{L})$. The result confirmed that all SGBs were much more favourable in adsorbing MB than commercial ACs at every pH level.

Some fluctuations on the removal rate of MB were observed in Figure 10. This could be due to the irregularity of the natural characteristic of materials in different types of SGB and it could also be due to the process of preparing the SGB. Since the three types of SGB have showed a similar MB adsorptive property at a higher $\mathrm{pH}$, it could be concluded that MB adsorption is more favourable in the alkaline water environment than acidic environment. This might be due to the excess $\mathrm{H}^{+}$ions competing with the MB cations for the adsorption sites in acidic water medium. With an increasing $\mathrm{pH}$ of the $\mathrm{MB}$ solution, the surface containing carboxyl groups will be deprotonated, resulting in an increase of negatively charged sites that favour the adsorption of MB due to electrostatic attraction. This means that in the case of treating acidic industrial water, a neutralisation of the water may be considered to achieve better adsorption of MB.

\subsection{Effect of Initial MB Concentrations on the Removal Rate of NSGB, CSGB and BSGB}

Figure 11 shows the removal rate of MB at the different initial concentrations of MB for NSGB, CSGB and BSGB. In general, it could be observed that BSGB had a higher MB removal rate than those NSGB and CSGB had, for every initial MB concentration. The higher initial MB concentration used the larger difference of MB removal rate. It also confirmed that BSGB was the most favourable adsorbent for MB adsorption. At the highest initial of MB concentration of $30 \mu \mathrm{M}(11.217 \mathrm{mg} / \mathrm{L})$, the BSGB, NSGB, CSGB gave the MB removal rate of 13.0034, 11.4292 and $10.9044 \mathrm{mg} / \mathrm{g}$ of the adsorbent respectively. This experiment was also to confirm that, due to the nature of BSGB which had a low lignin residual content, the SGB was able to have more adsorptive properties. This finding was in line with the finding from Begum and Mahbub (2013), who were suggesting that more cellulose content in SGB could effectively adsorb MB.

\subsection{Determining the Removal Capacity of NSGB, CSGB and BSGB}

Using the same data of various MB concentrations to construct Figure 11 and a fixed concentration of SGB of $0.833 \mathrm{~g} / \mathrm{L}$, the experimental data was fitted into adsorption isotherm models developed by Langmuir and Freundlich (Equations (6) and (7)). The results were shown in Table 2.

Table 2 shows that the MB experimental data were better fitted in Langmuir adsorption model for NSGB and CSGB than those in Freundlich isotherm model. This described that the monolayer adsorption of MB onto SGB surface with a finite number of identical sites took place. NSGB and CSGB had MB removal capacity of $84.7458 \mathrm{mg} / \mathrm{g}$ and $35.2113 \mathrm{mg} / \mathrm{g}$ respectively. On the contrary, CSGB showed approximately 10 folds stronger affinity of MB compounds onto SGB site than NSGB did. Indefinite figures were shown by BSGB using both adsorption isotherm models, suggesting that a larger variation of surface sites might be created after delignification. Further study using another theory of isotherm model might be required. 
Table 2. Langmuir and Freundlich parameters for MB adsorption on $0.833 \mathrm{~g} / \mathrm{L}$ NSGB, CSGB and BSGB at a measured $\mathrm{pH} 5$.

\begin{tabular}{ccccccc}
\hline \multirow{2}{*}{ SGB samples } & \multicolumn{3}{c}{ Langmuir parameters } & \multicolumn{3}{c}{ Freundlich parameters } \\
\cline { 2 - 7 } & $b$ & $X_{m}$ & $\mathrm{r}^{2}$ & $1 / \mathrm{n}$ & $\mathrm{K}$ & $r^{2}$ \\
\hline NSGB & 0.0124 & 84.7458 & 0.9852 & 0.9544 & 7.9141 & 0.9658 \\
CSGB & 0.1615 & 35.2113 & 0.9519 & 0.9703 & 4.9046 & 0.9517 \\
BSGB & Indefinite & Indefinite & 0.9611 & Indefinite & Indefinite & 0.8783 \\
\hline
\end{tabular}

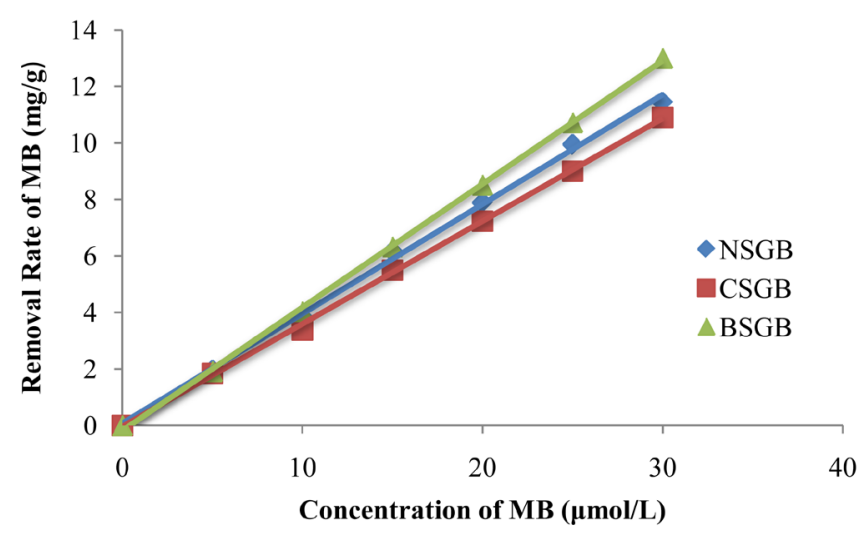

Figure 11. Removal rate of MB at different initial MB concentrations from a fixed concentration of $0.833 \mathrm{~g} / \mathrm{L}$ for NSGB, CSGB and BSGB. The equilibration time was 30 minutes and $\mathrm{pH} 5$.

\section{Conclusion}

In general, SGB was capable in removing MB in water medium whether the SGB contained lignin or mixture lingo-cellulose. SGB had 5 - 40 folds higher MB removal capability than commercial activated carbon, depending on the $\mathrm{pH}$ of water medium and the types of SGB. SGB showed a much better performance in adsorbing MB in alkaline environment than in acidic environment. Langmuir adsorption isotherm model was able to estimate the removal capacity of NSGB and CSGB at $84.7458 \mathrm{mg} / \mathrm{g}$ and $35.2113 \mathrm{mg} / \mathrm{g}$ respectively. An extremely higher MB removal capacity was found for BSGB due to the complexity of the surface site after chemical treatment, making it difficult to be explained using simple Langmuir and Freundlich isotherm models. BSGB with low lignin residue content was the most favourable adsorbent for MB adsorption. In conclusion, the cellulose rich BSGB could better remove organic dyes in neutral alkaline water environment.

\section{Acknowledgements}

The authors appreciated the supports from Singapore Polytechnic's Fund under ABE FYP Fund Vote Number 11-27801-50-2063 and SP TIEFA Vote Number: 11-27801-36-R185.

\section{References}

[1] Hennessey, R. (2012) Living In Colour: The Potential Dangers of Artificial Dyes. http://www.forbes.com/sites/rachelhennessey/2012/08/27/living-in-color-the-potential-dangers-of-artificial-dyes/

[2] Gupta, G.S., Shukla, S.P., Prasad, G. and Singh, V.N. (1992) China Clay as an Adsorbent for Dye House Wastewaters. Environmental Technology, 13, 925-936. http://dx.doi.org/10.1080/09593339209385228

[3] Shukla, S.P. and Gupta, G.S. (1992) Toxic Effects of Omega Chrome red ME and Its Treatment by Adsorption. Ecotoxicology and Environmental Safety, 24, 155-163. http://dx.doi.org/10.1016/0147-6513(92)90043-3

[4] Sokolowska-Gajda, J., Freeman, H.S. and Reife, A. (1996) Synthetic Dyes Based on Environmental Considerations: 2. Iron Complexes Formazan Dyes. Dyes and Pigments, 30, 1-20. http://dx.doi.org/10.1016/0143-7208(95)00048-8

[5] Ivanov, K., Gruber, E., Schempp, W. and Kirov, D. (1996) Possibilities of Using Zeolite as Filler and Carrier for Dye- 
stuffs in Paper. Das Papier, 50, 56-60. (In German)

[6] Bhat, R.V. and Mathur, P. (1998) Changing Scenario of Food Colours in India. Current Science, 74, 198-202.

[7] Slampova, A., Smela, D., Vondrackova, A., Jancarova, I. and Kuban, V. (2001) Determination of Synthetic Colorants in Foodstuffs. Chemicke Listy, 95, 163-168.

[8] Wagner, R.W. and Lindsey, J.S. (1996) Boron-Dipyrromethane Dyes for Incorporation in Synthetic Multi-Pigment Light-Harvesting Arrays. Pure and Applied Chemistry, 68, 73-80. http://dx.doi.org/10.1351/pac199668071373

[9] Wrobel, D., Boguta, A. and Ion, R.M. (2001) Mixtures of Synthetic Organic Dyes in a Photoelectronic Cell. Journal of Photochemistry and Photobiology A: Chemistry, 138, 7-22. http://dx.doi.org/10.1016/S1010-6030(00)00377-4

[10] Halim, H.N.A. and Mee, K.L.K. (2011) Adsorption of Basic Red 46 by Granular Activated Carbon in a Fixed Bed Column. IPCBEE, 12, 263-267.

[11] Pereira, L. and Alves, M. (2012) Chapter 4: Dyes-Environmental Impact and Remediation. In: Malik, A. and Grohmann, E., Eds., Environmental Protection Strategies for Sustainable Development, Strategies for Sustainability, Springer Science + Business Media B.V., Dordrecht, 111-154. http://dx.doi.org/10.1007/978-94-007-1591-2_4

[12] Sigma-Aldrich, Co. (2014) Sigma-Aldrich. http://www.sigmaaldrich.com/singapore.html

[13] Nigam, P., Armour, G., Nanat, I.M., Singh, D. and Marchant, R. (2000) Physical Removal of Textile Dyes from Effluents and Solid-State Fermentation of Dye-Adsorbed Agricultural Residues. Bioresource Technology, 72, 219-226. http://dx.doi.org/10.1016/S0960-8524(99)00123-6

[14] Xu, X., Gao, B.Y., Yue, Q.Y. and Zhong, Q.Q. (2010) Preparation and Utilisation of Wheat Straw Bearing Amine Groups for the Sorption of Acid and Reactive Dyes from Aqueous Solutions. Journal of Hazardous Materials, 182, 1-9. http://dx.doi.org/10.1016/j.jhazmat.2010.03.071

[15] Kanawade, S.M. and Gaikwad, R.W. (2011) Removal of Dyes from Dye Effluent by Using Sugarcane Bagasse Ash as an Adsorbent. International Journal of Chemical Engineering and Applications, 2, 202-206. http://dx.doi.org/10.7763/IJCEA.2011.V2.103

[16] Kavitha, D. and Namasivayam, C. (2007) Recycling Coir Path, an Agricultural Solid Waste, for the Removal of Procion Orange from Wastewater. Dyes Pigments, 74, 237-248. http://dx.doi.org/10.1016/j.dyepig.2006.01.040

[17] Diffen (2013) Absorption vs. Adsorption. http://www.diffen.com/difference/Absorption vs Adsorption

[18] Rashed, M.N. (2013) Adsorption Technique for the Removal of Organic Pollutants from Water and Wastewater. Organic Pollutants-Monitoring, Risk and Treatment, InTech Open. http://www.intechopen.com/download/get/type/pdfs/id/42059

[19] Bhatnagar, A., Hogland, W., Marques, M. and Sillanpaa, M. (2013) An Overview of the Modification Methods of Activated Carbon for Its Water Treatment Applications. Chemical Engineering Journal, 219, 499-511. http://dx.doi.org/10.1016/j.cej.2012.12.038

[20] Okada, K., Yamamoto, N., Kameshima, Y. and Yasumori, A. (2003) Porous Properties of Activated Carbons from Waste Newspaper Prepared by Chemical and Physical Activation. Journal of Colloid and Interface Science, 262, 179193. http://dx.doi.org/10.1016/S0021-9797(03)00107-3

[21] Guo, Y.P. and Rockstraw, D.A. (2007) Activated Carbons Prepared from Rice Hull by One-Step Phosphoric Acid Activation. Microporous and Mesoporous Materials, 100, 12-19. http://dx.doi.org/10.1016/j.micromeso.2006.10.006

[22] Djati Utomo, H., Ong, Z.S., Tan, W.T.E., Lee, Y.S.D. and Li, P. (2013) Thermally Processed Natural Waste from Woodwaste for Organic Water Contaminant Uptake. In: Shu, L., Jegatheesan, V., Pandey, A., Virkutyte, J. and Utomo, H.D., Eds., Solutions to Environmental Challenges through Innovations in Research, AsiaTech Publishers Inc., New Delhi, 84-101.

[23] Raghuvanshi, S.P., Singh, R. and Kaushik, C.P. (2004) Kinetic Study of Methylene Blue Dye Bio-Adsorption on Bagasse. Applied Ecology and Environmental Research, 2, 35-43. http://dx.doi.org/10.15666/aeer/03035043

[24] Azhar, S.S., Liew, A.G., Suhardy, D., Hafiz, K.F. and Hatim, M.D.I. (2005) Dye Removal from Aqueous Solution by Using Adsorption on Treated Sugarcane Bagasse. American Journal of Applied Sciences, 2, 1499-1503. http://dx.doi.org/10.3844/ajassp.2005.1499.1503

[25] Abdullah, A.G.L., Salleh, M., Mazlina, S., Megat, M.J., Noor, M., Osman, M.R., Wagiran, R. and Sobri, S. (2005) Azo Dye Removal by Adsorption Using Waste Biomass: Sugarcane Bagasse. International Journal of Engineering \& Technology, 2, 8-13.

[26] Begum, H.A. and Mahbub, M.K. (2003) Effectiveness of Carboxymethyl Cellulose for the Removal of Methylene Blue from Aqueous Solution. Dhaka University Journal of Science, 61, 193-198.

[27] Rowell, R.M. (2005) Handbook of Wood Chemistry and Wood Composites. CRC Press, Boca Raton, 62.

[28] Mulinari, D.R., Voorwald, G.H.J.C., Cioffie, M.O.H., Rocha, G.J. and Da Silva, M.L.C.P. (2010) Surface Modification of Sugarcane Bagasse Cellulose and Its Effect on Mechanical and Water Absorption Properties of Sugarcane Bagasse 
Cellulose/HDPE Composites. Bioresource, 5, 661-671.

[29] Djati Utomo, H., Ong, X.C., Lim, S.M.S., Ong, G.C.B. and Li, P. (2013) Thermally Processed Sewage Sludge for Methylene Blue Uptake. International Biodeterioration \& Biodegradable International Biodeterioration, 85, 460-465. http://dx.doi.org/10.1016/j.ibiod.2012.12.004

[30] Filho, N.C., Venancio, E.C., Barriquello, M.F., Hechenleitner, A.W.W. and Pineda, A.G.G. (2007) Methylene Blue Adsorption onto Modified Lignin from Sugar Cane Bagasse. Ecletica Química, 32, 63-70. 